Claremont Colleges

Scholarship@ Claremont

Pitzer Faculty Publications and Research

Pitzer Faculty Scholarship

$12-1-2008$

\title{
Integrating Development and Evolution in Psychology: Looking Back, Moving Forward
}

David S. Moore

Pitzer College

\section{Recommended Citation}

Moore, David. "Integrating Development and Evolution in Psychology: Looking Back, Moving Forward." Editorial. Integrating Development and Evolution in Psychology. Spec. issue of New Ideas in Psychology 26.3 (2008): 327-331.

This Article - postprint is brought to you for free and open access by the Pitzer Faculty Scholarship at Scholarship @ Claremont. It has been accepted for inclusion in Pitzer Faculty Publications and Research by an authorized administrator of Scholarship @ Claremont. For more information, please contact scholarship@cuc.claremont.edu. 
Running head: Development and Evolution

The content of this open-access post-print article is the same as that contained in the published article with the following reference:

Moore, D. S. (2008). Integrating development and evolution in psychology: Looking back, moving forward [Editorial]. New Ideas in Psychology, 26, 327 - 331.

\section{Editorial}

Integrating development and evolution in psychology:

Looking back, moving forward

David S. Moore

Pitzer College \& Claremont Graduate University

July 19,2007 


\section{Editorial}

Integrating development and evolution in psychology:

Looking back, moving forward

Modern psychology, from its inception, has been informed by ideas imported from related fields of inquiry. It is widely acknowledged, for example, that Sigmund Freud's familiarity with Darwin's theory of evolution contributed to the development of his own ideas about the determinants of psychological functioning (Sulloway, 1992). Likewise, the founder of the first psychology laboratory in the United States, Edward Titchener, explicitly used conceptualizations imported from other sciences as he attempted to position our fledgling discipline among these fields, writing in 1898 "we can represent modern psychology as the exact counterpart of modern biology" (p. 450). This reliance on other sciences_-biology, in particular- has continued into recent times, as evolutionary psychologists (Buss, 2007; Pinker, 2002) have turned to evolutionary biology for ideas that might help explain some of our behaviors, and as quantitative behavior geneticists (Plomin, DeFries, \& Fulker, 2006; DiLalla, 2004) have turned to population genetics for ideas that might help explain the transmission of behavioral characteristics across generations and the distribution of such characteristics across populations.

In many quarters - in the popular press and in introduction to psychology textbooks, in particular - the ideas generated by evolutionary psychology and behavior genetics have been met with excitement and a sense that our field is maturing. However, as these branches of psychology have become more prominent in the field, new ideas that are not necessarily consistent with their tenets have been surfacing in the neurosciences, 
genetics, developmental biology, and philosophy, and it is these latter ideas that stand to shape psychological theory in the decades to come. It has often served psychology well in the past to attend to advances in allied fields, but if we are to benefit from importing biological ideas into our field, we must be sure that our biology is up to date and accurate (Finlay, 2007).

Among the psychologists who have worked to infuse state-of-the-art understandings of biology into psychology is Gilbert Gottlieb, who died in the summer of 2006, and to whom this special issue is dedicated. As a young man drafted into the army during the Korean War and assigned to work in counter-intelligence in Austria, Gottlieb was struck by how the people in Austria who had been displaced by World War II varied in their responses to the stresses associated with their dislocation; some people appeared to be considerably more resilient than others. This experience induced Gottlieb to pursue a degree in psychology when he returned to the United States, and ultimately led him to seek a PhD in Clinical and Experimental Psychology in Duke University's joint psychology-zoology training program in animal behavior. While at Duke, Gottlieb's approach to psychology was importantly influenced by Peter H. Klopfer, then a member of Duke's zoology department, and ultimately one of Gottlieb's significant mentors. In this context, Gottlieb followed his interest in the origins of behavioral variability by empirically studying imprinting in birds, a topic that led him to read widely in the literatures of evolutionary and developmental biology, and that left him with a very different knowledge base than many of his contemporaries in psychology. In addition, his intellectual explorations as an undergraduate had brought him into contact with the notion of interactionism, and these ideas left him with a lifelong perspective that emphasized the 
dynamic interplay between "biological" and "experiential" factors during the development of behavioral characteristics.

Among Gottlieb's significant discoveries were the following two facts: 1) that some of the experiential factors that contribute to behavioral development are encountered prior to birth, and (2) that some of the important experiential factors encountered after birth are non-obvious (in the sense that they would be unlikely to draw an experimenter's attention prior to the sort of careful analysis required to reveal their effects on development). These findings were among the large body of research—much of it reviewed in the papers of this special issue - that challenged a notion prevalent in psychology since the middle of the $20^{\text {th }}$ century, the idea that some behaviors are "instinctive," "hardwired," "genetic," or otherwise determined prior to the actual unfolding of development (Gottlieb, 1997).

Gottlieb never manipulated genes in his elegant experiments, and as a result, his findings typically emphasized the contributions of experiential factors to behavioral development. Nevertheless, his detailed understanding of biology allowed him to acknowledge the importance of genetic factors in development while maintaining that such factors could never independently produce full-blown behavioral traits. Arguing on the basis of psychobiological data, Gottlieb maintained that development could best be characterized as a probabilistic process involving both genetic and non-genetic factors. In explicating his conception of probabilistic epigenesis, he explicitly held (see, for example, Gottlieb, 2004) that development always results from interactions among developmental resources that includes both types of factors, a position that became one of the pillars of developmental systems theory; the latter collection of ideas has become increasingly prominent in 
psychological writings in the past decade (Nelson, 2007; Oyama, Griffiths, \& Gray, 2001; Thelen \& Smith, 1998).

As new data from various branches of biology have poured into our digital libraries, it has become clear that the biological ideas we should be importing into psychology are those consistent with Gottlieb's position, not necessarily with the positions characteristic of evolutionary psychology or quantitative behavior genetics. Although the contributors to this special issue have varying stances regarding the extent to which they believe these positions can be integrated, they generally agree that a developmental approach like the one Gottlieb advocated will yield essential insights into the origins of our psychological characteristics; in some cases, they are openly dubious about the prospect of quantitative behavior genetics or evolutionary psychology yielding similarly valuable insights. In these cases, this lack of faith in these otherwise popular ideas results from an awareness that biologists no longer subscribe to the sort of genetic determinism that characterized biology in the middle of the $20^{\text {th }}$ century and that remains embedded in the often-unstated assumptions of evolutionary psychology and quantitative behavior genetics. Instead, contemporary biologists acknowledge the importance of epigenetic processes in development, lending support to Gottlieb's view of development (Harper, 2005; Jablonka \& Lamb, 2005; Meaney \& Szyf, 2005). As the contributors to this special issue see it, the ideas associated with this view represent valuable new contributions to psychology.

Although the ideas discussed in the following papers have only begun to attract the attention of significant numbers of psychologists in recent years, many of these ideas have a longer history in biology. Consequently, it is helpful to begin with an historical 
examination of the intellectual contexts that contributed to these ideas, and to consider the debates that have ensued as scholars have begun to grapple with the challenges that new data and theory from the developmental sciences have presented to an older biology. Griffiths and Tabery (2008) trace the 1995 dispute between Gottlieb and several quantitative behavior geneticists to an earlier (1920's and 1930's) disagreement between R.A. Fisher and L. Hogben about the nature of gene-environment interaction; along the way, they provide helpful information regarding the origins and shifting meanings of the organizing concepts norm of reaction and reaction range. In contrast to Gottlieb, Griffiths and Tabery see the approaches of developmentally-oriented psychobiologists and biometrically-oriented behavior geneticists as complementary and equally valid, and they suggest that knowledge gleaned from the two projects can be integrated. The key to resolving the dispute, they suggest, is recognizing the extent to which scientists of different theoretical orientations are concerned with potential variation that has not yet been detected in any real population. Finally, the distinction they use between two different conceptions of the gene-developmental/molecular genes and Mendelian genes - is one that has the potential to clarify thinking about the origins of traits, and as such represents a conceptual advance that could very well drive future scientific syntheses.

In The growth of developmental thought: Implications for a new evolutionary psychology, Lickliter (2008) considers how recent advances in the developmental sciences might contribute to the emergence of a cohesive theory of development, heredity, and evolution. Although development and evolution were understood in Darwin's time to be integrally related to one another, the Modern Synthesis devised by 
biologists in the early $20^{\text {th }}$ century was a theory of evolution that gave no role whatsoever to developmental phenomena. As a result, most evolutionary psychologists today make the mistake of ignoring the role of development in evolution, and continue to accept the conceptual separation between nature (genes) and nurture that characterized the Modern Synthesis. In an effort to motivate psychologists to seek a developmentally plausible evolutionary psychology, Lickliter both criticizes the unstated assumption of genetic determinism that lies at the heart of current evolutionary psychology, and reviews data from a variety of sources, all of which support Gottlieb's contention that behavioral phenotypes emerge epigenetically from the bidirectional interaction of genetic and nongenetic resources, resources that constitute developing biological systems. These data further indicate that behavioral phenotypes themselves can ultimately influence subsequent evolution. In assembling this information, Lickliter has proffered a cogent presentation of the core tenets of developmental systems theory. The developmentallybased evolutionary psychology Lickliter envisions would incorporate the idea that a satisfying understanding of evolution depends on a satisfying understanding of development, because it is development that produces the phenotypes that natural selection operates on in the first place.

Like the authors of the first two papers in this special issue, Moore (2008) believes that research psychologists in general would benefit from adopting a developmental perspective informed by emerging understandings in molecular, developmental, and evolutionary biology. However, he foresees a major obstacle to the establishment of a theory that can explain both data collected in studies of population genetics and data collected in studies of development, because population geneticists have traditionally attempted to 
explain variation in traits across populations whereas developmentalists have traditionally attempted to explain the emergence of traits in individual organisms. Although both approaches were designed — and seem to their adherents—-to address questions about the factors that contribute to the appearance of our traits, Moore finds the two approaches to be incompatible. Theoretically, it might be possible for the population-based approach of behavior geneticists to proceed independently of the organism-based approach of developmental scientists, but because evolutionary phenomena (which occur at the level of populations) have important influences on developmental phenomena, and because developmental phenomena (which occur at the level of individual organisms) have important effects on evolution, a theoretical framework that can accommodate data collected at both levels of analysis would seem to be imperative. However, because the data of molecular and developmental biology have now made it clear that genetic factors cannot independently cause the development of phenotypic characteristics, it remains unclear what a unified theory encompassing both population-level and organism-level phenomena would look like.

A potentially fruitful path to such a theory might be discovered by studying the interdisciplinary field of evolutionary-developmental biology—Evo-Devo to its practitioners - the ascendancy of which represents a sea-change in biology; for the first time since the Modern Synthesis was completed in the 1930's, the past decade has seen widespread and serious consideration of developmental questions by scholars of diverse fields including evolutionary biology, genetics, paleontology, and molecular biology. In the final, forward-looking article of this special issue, Robert (2008) envisions a new subfield of psychology called "evolutionary developmental psychobiology," which he sees 
as being analogous to Evo-Devo within biology. After taking a brief critical look at how evolutionary theory has been utilized by psychologists to date, Robert describes some of the research questions - and empirical results - that have emerged from laboratories operating within the Evo-Devo paradigm; the examples presented illustrate the advantages that accrue when developmental and evolutionary analyses are successfully integrated within a single interdisciplinary project. Robert's suggestion that the behavioral sciences would benefit from adopting a similar approach is supported by a consideration of the valuable scientific insights reaped from Gottlieb's work, a rare example of a psychological research program motivated by both evolutionary and developmental questions. In the interest of providing helpful guidance, Robert ends his paper by outlining what it would really mean for psychologists to begin taking both developmental and evolutionary considerations seriously as they plan their research.

Psychologists have always turned to biologists, among other scholars, for ideas about how to approach psychological research questions in a productive manner. Moving forward, it will be important to develop new ideas in psychology that are consistent with new ideas in biology; biologists are increasingly concerned with developmental questions, and have consequently generated data that have forced them to reject some of their older ideas about the origins of our characteristics. As psychologists are increasingly exposed to new ideas in biology, the idea that behaviors can be determined by genetic factors independently of development — or that evolutionary analysis alone can provide a satisfactory explanation of our psychological characteristics — will give way to new ideas consistent with the developmental systems perspective championed by Gilbert Gottlieb throughout his illustrious scientific career. 


\section{References}

Buss, D. M. (2007). Evolutionary psychology: The new science of the mind ( $3^{\text {rd }}$ ed.). Needham Heights, MA: Allyn \& Bacon.

DiLalla, L. F. (2004). Behavior genetics principles: Perspectives in development, personality, and psychopathology. Washington, DC: American Psychological Association.

Finlay, B. L. (2007). Endless minds most beautiful.Developmental Science, 10, 30 - 34.

Gottlieb, G. (1997). Synthesizing nature-nurture: Prenatal roots of instinctive behavior. Mahwah, NJ: Erlbaum.

Gottlieb, G. (2004). Normally occurring environmental and behavioral influences on gene activity: From central dogma to probabilistic epigenesis. In C. G. Coll, E. L. Bearer, \& R. M. Lerner (Eds.), Nature and nurture: The complex interplay of genetic and environmental influences on human behavior and development (pp. 85 -106). Mahwah, NJ: Lawrence Erlbaum Associates Publishers.

Griffiths, P. E. \& Tabery, J. (2008). Behavioral genetics and development: Historical and conceptual causes of controversy. New Ideas in Psychology, 26, 332 - 352.

Harper, L. V. (2005). Epigenetic inheritance and the intergenerational transfer of experience. Psychological Bulletin, 131, $340-360$.

Jablonka, E., \& Lamb, M. J. (2005). Evolution in four dimensions: Genetic, epigenetic, behavioral, and symbolic variation in the history of life. Cambridge, MA: MIT.

Lickliter, R. (2008). The growth of developmental thought: Implications for a new evolutionary psychology. New Ideas in Psychology, 26, $353-369$.

Meaney, M. J., \& Szyf, M. (2005). Maternal care as a model for experience-dependent chromatin plasticity? Trends in Neurosciences, 28, $456-463$. 
Moore, D. S. (2008). Individuals and populations: How biology's theory and data have interfered with the integration of development and evolution. New Ideas in Psychology, 26, 370 -386.

Nelson, K (2007). Young minds in social worlds: Experience, meaning, and memory. Cambridge, MA: Harvard University Press.

Oyama, S., Griffiths, P. E., \& Gray, R. D. (2001). Cycles of contingency: Developmental systems and evolution. Cambridge, MA: MIT Press.

Pinker, S. (2002). The blank slate: The modern denial of human nature. New York: Viking.

Plomin, R., DeFries, J. C., \& Fulker, D. W. (2006). Nature and nurture during infancy and early childhood. Cambridge: Cambridge University Press.

Robert, J. S. (2008). Taking old ideas seriously: Evolution, development, and human behavior. New Ideas in Psychology, 26, 387 - 404.

Sulloway, F. J. (1992). Freud, biologist of the mind. Cambridge, MA: Harvard University Press.

Thelen, E., \& Smith, L. B. (1998). Dynamic systems theories. In W. Damon (Series Ed.) \& R. M. Lerner (Vol. Ed.), Handbook of child psychology: Vol. 1. Theoretical models of human development ( $5^{\text {th }}$ ed., pp. 563-634). New York: Wiley.

Titchener, E. B. (1898). The postulates of a structural psychology. The Philosophical Review, 7, $449-465$. 


\section{Author Note}

\section{David S. Moore}

Pitzer College, 1050 N. Mills Avenue, Claremont, CA 91711, USA

E-mail address: dmoore@pitzer.edu 